\title{
Anthocyanin and proanthocyanidin contents, antioxidant activity, and in situ degradability of black and red rice grains
}

\author{
Kenji Hosoda ${ }^{1,2, *}$, Hideki Sasahara ${ }^{3}$, Kei Matsushita ${ }^{3}$, Yasuaki Tamura ${ }^{4}$, \\ Makoto Miyaji ${ }^{1}$, and Hiroki Matsuyama ${ }^{5}$
}

\footnotetext{
* Corresponding Author: Kenji Hosoda Tel: +81-96-242-7747, Fax: +81-96-242-7747, E-mail: kenhoso@affrc.go.jp
}

'Institute of Livestock and Grassland Science, National Agriculture and Food Research Organization (NARO), Nasushiobara, Tochigi 329-2793, Japan

2 Kyushu Okinawa Agricultural Research Center, NARO, Koshi, Kumamoto 861-1192, Japan

${ }^{3}$ Central Region Agricultural Research Center, NARO,

Joetsu, Niigata 943-0193, Japan

${ }^{4}$ Tropical Agriculture Research Front, Japan International Research Center for Agricultural

Sciences, Ishigaki, Okinawa 907-0002, Japan

${ }^{5}$ Faculty of Agriculture, Yamagata University, Tsuruoka, Yamagata 997-8555, Japan

ORCID

Kenji Hosoda

https://orcid.org/0000-0002-9330-3152

Hideki Sasahara

https://orcid.org/0000-0002-3606-508X

Kei Matsushita

https://orcid.org/0000-0002-7965-6824

Yasuaki Tamura

https://orcid.org/0000-0002-0112-8730

Makoto Miyaji

https://orcid.org/0000-0002-8760-5680

Hiroki Matsuyama

https://orcid.org/0000-0001-6418-6340

Submitted Sept 5, 2017; Revised Jan 11, 2018 Accepted Feb 6, 2018
Objective: An experiment was conducted to assess the antioxidant contents and activities of colored rice grains and to evaluate their nutritive characteristics in terms of chemical composition and in situ ruminal degradation.

Methods: Ten cultivars of colored rice grains (Oryza sativa L.) collected from several areas of Japan were studied, and control rice without pigment, maize, barley, and wheat grains were used as control grains. Their chemical compositions, pigment, polyphenol contents, total antioxidant capacity (TAC), and degradation characteristics were determined.

Results: The starch contents of the colored rice grains were in the range of $73.5 \%$ to $79.6 \%$, similar to that of the control rice grain. The black and red rice grains contained anthocyanin (maximum: 5,045.6 $\mu \mathrm{g} / \mathrm{g}$ ) and proanthocyanidin (maximum: 3,060.6 $\mu \mathrm{g} / \mathrm{g}$ ) at high concentrations as their principal pigments, respectively. There were significantly $(\mathrm{p}<0.05)$ positive relationships among the pigment contents, polyphenol content, and TAC values in the colored and control rice grains, indicating that the increase in pigment contents also contributed to the increased polyphenol content and TAC values in the colored rice grains. The dry matter and starch degradation characteristics, as represented by $c$ (fractional degradation rate of slowly degradable fraction) and by the effective degradability, of the colored rice grains and the control rice grain were ranked as follows among commonly used grains: wheat $>$ barley $\geq$ rice $>$ maize. The colored rice grains also included the most-digestible starch, since their potential degradable fraction and actual degradability at $48 \mathrm{~h}$ incubation were almost $100 \%$. Conclusion: Colored rice grains have high potential to be used as antioxidant sources in addition to starch sources in ruminants.

Keywords: Anthocyanin; Antioxidant Activity; Black Rice; In situ Degradability; Proanthocyanidin; Red Rice

\section{INTRODUCTION}

Although maize, barley, and wheat grains are widely used as carbohydrate sources in the ruminant diet, pigment-free rice grains can be used in place of those grains [1]. There is increasing demand for the domestic production of rice crops to create a stable supply of carbohydrate feedstuff that is more stable than a supply that is dependent on imported grains. This is also because the cultivation of rice crops rather than maize, barley and wheat crops, is appropriate for the humid climates of East Asia, including Japan. In fact, the production of rice crops as feedstuff and their availability as feed for ruminant animals have been rapidly increasing in Japan in recent years [2].

Oxidative stress, which is quite naturally produced in life activity of living organisms, elicits oxidative damage of cellular macromolecules, cell death, and structural tissue damage [3]. It is generally known that ruminant animals such as cattle, sheep and goats can undergo 
oxidative stress affected by nutritional management, stage in the production cycle, and environmental factors [4]. The incidence of several diseases in farm animals is thought to be associated with oxidative stress [3]. Thus, these previous reports suggest that the use of antioxidant substances in ruminant feed could help prevent production loss due to oxidative stress.

Of rice cultivated around the world, the types that are most widely cultivated are pigment free, and the rest have colored grains containing pigment. The types of colored rice include black and red rice, and their main pigments are anthocyanin and proanthocyanidin, respectively [5]. It has been reported that both of these pigments exhibit strong antioxidant activity [6]. Therefore, black and red rice grains have considerable potential as sources of antioxidants in addition to being carbohydrate sources for ruminant animals.

Since antioxidants in foods have attracted increasing attention, a number of rice cultivars with colored grains have been developed at local governmental institutes in Japan [7]. They have been improved to adapt to various types of climatic conditions in Japan as well as to have high contents of functional pigments. However, no studies have yet been performed to assess the value of these colored rice cultivars bred in Japan as ruminant feedstuffs. The objective of the present study was to assess the nutritive characteristics of 10 cultivars of colored rice grains in terms of their chemical composition and their in situ ruminal degradation, as well as their antioxidant contents and activities.

\section{MATERIALS AND METHODS}

\section{Animal care}

The animal trial plan was approved by the Animal Ethical and Care Committee of the Institute of Livestock and Grassland Science, National Agriculture and Food Research Organization (NARO), and the animals were cared for according to the Animal Care Guideline of this committee during the trial.

\section{Grain samples}

Ten rice cultivars with colored rice grains (Oryza sativa L.; black rice: Minenomurasaki, Asamurasaki, Okuno-murasaki, Sayomurasaki; and red rice: Yuyakemochi, Hokuriku-Aka212, Benigoromo, Beniroman, Benizomemochi, Shuu-Aka8745), one control cultivar with pigment-free rice grains (Oryza sativa L.; Nipponbare) and three feed grains (maize, barley, and wheat) were used. The control rice cultivar and the three feed grains were enrolled as a rice control without pigment and as commonly-used grain controls with different ruminal degradation characteristics [8], respectively. The hulled rice grains were obtained from governmental institutes located in several areas of Japan (the Tohoku, Hokuriku, Tokai, Chugoku and Kyushu regions). They were cultivated under the conventional conditions of their institutes and harvested at the maturing stage. The harvested grains (40 to $60 \mathrm{~kg}$ ) were individually mixed well by a shovel, and part of them (approximately $1 \mathrm{~kg}$ ) were used for the present study. The maize, barley, and wheat grains, which were imported, were obtained from a feed company.

\section{In situ study}

A nylon bag method was used to determine the dry matter (DM) and starch degradability of the grains by suspending bags in the rumens of two rumen-fistulated Holstein steers, which were $520.0 \pm 28.3 \mathrm{~kg}$ in live weight and 2.0 years old. The animals were fed a diet containing timothy hay, soybean meal, and flaked maize at the ratio of 65:23:12 on a DM basis to meet the maintenance energy requirements of the Holstein steers [9], and also had free access to fresh water and mineral blocks. The animals were adapted to the diet for 2 weeks prior to the start of the ruminal incubations. Grains were ground through a 2-mm screen using a Wiley mill, since a milling process that provides particles $<2 \mathrm{~mm}$ in size is required to maximize rice starch digestion in ruminants [8]. Approximately $7 \mathrm{~g}$ of the ground material was accurately weighed into nylon bags (10 $\mathrm{cm} \times 20 \mathrm{~cm}, 53-\mu \mathrm{m}$ pore size; Bar Diamond, Parma, ID, USA), and the bags were tightly sealed by rubber bands. Nylon bags containing materials in a large-mesh net with weight were placed in the rumen of each animal via the ruminal cannula after the bags were soaked in lukewarm water. The bags were incubated in reverse order for $0,3,6,9,12,24$, and $48 \mathrm{~h}$ and removed at a common time. Immediately after removal, all incubated bags were immersed in ice-cold water (for $10 \mathrm{~min}$ ) to stop all microbial activity. All bags were washed in a domestic washing machine (PS-555; Hitachi, Tokyo, Japan) under running tap water for 20 to 25 min until the effluent water was clear, and then washed again by hand with cold tap water. The 0 -hour bags were not incubated in the rumen but instead were immersed in water $\left(40^{\circ} \mathrm{C}\right)$ for $1 \mathrm{~h}$ to measure the soluble fraction before the washing procedure. They were then dried at $60^{\circ} \mathrm{C}$ for $48 \mathrm{~h}$ to determine the DM content, and the residues were used for starch assays. The ruminal incubation was performed in quadruplicate for each grain. The replication was conducted with 2 replicates per each animal at different period ( 2 animals $\times 2$ periods).

Data from this in situ study were fitted to the model of Ørskov and McDonald [10]: $p=a+b \times\left(1-\mathrm{e}^{-c t}\right)$, where $p=$ rumen disappearance after thours; $a, b$, and $c=$ model constants ( $a=$ soluble and very rapidly degradable fraction; $b=$ slowly degradable fraction; and $c=$ fractional degradation rate of $b$ ). Effective degradability (ED) was calculated as $\mathrm{ED}=a+[(b \times c)$ $/(c+k)$ ] [11], where $a, b$, and $c$ are as described above and $k$ is the fractional rate of passage from the rumen, with a constant $k$ value of $0.05 / \mathrm{h}$. Those calculations were carried out using the computer program 'Neway' (X. B. Chen, International Feed Resources Unit, Aberdeen, UK) based on the models of 
Ørskov and McDonald [10] and McDonald [11].

\section{Chemical analysis}

The samples were ground with a 1-mm screen prior to the assays. The DM of the samples was measured by drying them at $135^{\circ} \mathrm{C}$ for $2 \mathrm{~h}$. The crude protein, ether extract, and crude ash of the samples were analyzed according to AOAC Methods $976.05,920.39$, and 942.05 , respectively [12]. The amount of organic matter was calculated as the weight loss after ashing. The neutral detergent fiber (aNDFom) was determined using AOAC Method 2002.04 with thermostable $\alpha$-amylase [12] and expressed free of ash. The acid detergent fiber (ADFom) of the samples was analyzed by the methods of Van Soest et al [13] and expressed free of ash.

For assays of starch, amylose, anthocyanin, proanthocyanidin, polyphenol and antioxidant activity, the samples were further ground with a $0.25-\mathrm{mm}$ screen. A commercial kit (Total Starch assay kit; Megazyme International, Wicklow, Ireland) based on AOAC Method 996.11 was used to determine the starch content in the samples. The amylose content of the samples was measured by the colorimetric iodine method according to the procedure of Juliano [14]. The anthocyanin, expressed in terms of cyanidin-3-glucoside equivalents, in the samples was measured by the $\mathrm{pH}$ differential method (AOAC Method 2005.02; [15]). Proanthocyanidin, expressed in terms of $(+)$-catechin equivalents, was colorimetrically assayed by the vanillin method [16] with sample extracts following to procedure described previously [17]. For polyphenol and total antioxidant capacity (TAC) assays, sample extracts were prepared by the procedure of Suda et al [17]. Polyphenol expressed in terms of gallic acid equivalents and TAC expressed in terms of the copper-reducing power of the sample extracts were determined by the Folin-Ciocalteu method [18] and using a commercially-available kit (PAO; Nikken SEIL, Shizuoka, Japan), respectively.

\section{Statistical analysis}

All statistical calculations were performed using SAS [19]. The data from the in situ study were subjected to the MIXED procedure using the following model: $Y_{\mathrm{ijk}}=\mu+\mathrm{G}_{\mathrm{i}}+\mathrm{A}_{\mathrm{j}}+\varepsilon_{\mathrm{ijk}}$, where $Y_{i j k}$ is the dependent variable, $\mu$ is the overall mean, $G_{i}$ is the fixed effect of the grain, $A_{j}$ is the random effect of the animal, and $\varepsilon_{\mathrm{ijk}}$ is the random residual error. For data on the pigments, polyphenol contents, and TAC, the above model without the effect of animal was used. The means were compared using a multiple comparison test (Tukey) following a significant main effect. A contrast orthogonal test was also conducted for data on the pigments, polyphenol contents, and TAC between control, black and red rice groups. The relationships between values (chemical compositions, pigments, polyphenol contents, TAC, and in situ degradability model parameters) were detected using the CORR procedure. A value of $\mathrm{p}<0.05$ was considered to show statistical significance.

\section{RESULTS}

\section{Chemical composition}

The chemical compositions of the grains studied are shown in Table 1. The starch contents in the rice cultivars were in the range of $73.5 \%$ to $79.6 \%$. The amylose contents of the rice cultivars varied between $1.9 \%$ to $17.4 \%$.

Pigments, polyphenol contents, and TAC values In Table 2, the pigments, polyphenol contents, and TAC in

Table 1. Chemical compositions of rice, maize, barley, and wheat grains (\% DM)

\begin{tabular}{|c|c|c|c|c|c|c|c|}
\hline & $\mathrm{OM}$ & $\mathrm{CP}$ & $\mathrm{EE}$ & Starch & Amylose & ADFom & aNDFom \\
\hline \multicolumn{8}{|l|}{ Control rice } \\
\hline Nipponbare & 98.6 & 8.8 & 3.0 & 78.7 & 14.3 & 1.4 & 4.5 \\
\hline \multicolumn{8}{|l|}{ Black rice } \\
\hline Minenomurasaki & 98.5 & 10.1 & 2.6 & 73.5 & 1.9 & 1.8 & 6.6 \\
\hline Asamurasaki & 98.4 & 8.0 & 3.5 & 75.5 & 2.1 & 1.8 & 6.6 \\
\hline Okuno-murasaki & 98.6 & 7.8 & 2.7 & 79.6 & 13.8 & 1.5 & 9.3 \\
\hline Sayomurasaki & 98.3 & 8.9 & 2.9 & 75.6 & 2.5 & 2.5 & 8.0 \\
\hline \multicolumn{8}{|l|}{ Red rice } \\
\hline Yuyakemochi & 98.4 & 8.3 & 3.0 & 76.5 & 2.3 & 2.8 & 6.1 \\
\hline Hokuriku-Aka212 & 98.4 & 7.7 & 3.6 & 75.6 & 13.1 & 3.0 & 8.0 \\
\hline Benigoromo & 98.4 & 8.7 & 2.5 & 76.7 & 12.6 & 2.2 & 5.6 \\
\hline Beniroman & 98.5 & 9.4 & 2.7 & 77.4 & 17.4 & 2.9 & 7.4 \\
\hline Benizomemochi & 98.1 & 9.1 & 3.5 & 75.3 & 2.9 & 4.1 & 6.6 \\
\hline Shuu-Aka8745 & 98.2 & 7.7 & 4.3 & 74.7 & 12.0 & 4.1 & 8.3 \\
\hline Maize & 98.7 & 8.1 & 4.2 & 72.3 & 21.5 & 3.0 & 14.2 \\
\hline Barley & 98.1 & 11.9 & 2.6 & 52.7 & 13.7 & 7.2 & 19.7 \\
\hline Wheat & 98.2 & 15.8 & 1.8 & 60.7 & 14.1 & 3.7 & 10.8 \\
\hline
\end{tabular}

DM, dry matter; OM, organic matter; $C P$, crude protein; EE, Ether extract; ADFom, acid detergent fiber; aNDFom, neutral detergent fiber. 
Table 2. Pigment and polyphenol contents $(\mu \mathrm{g} / \mathrm{g})$ and total antioxidant capacity $(\mathrm{TAC}, \mu \mathrm{mol} / \mathrm{g}$ ) of rice grains

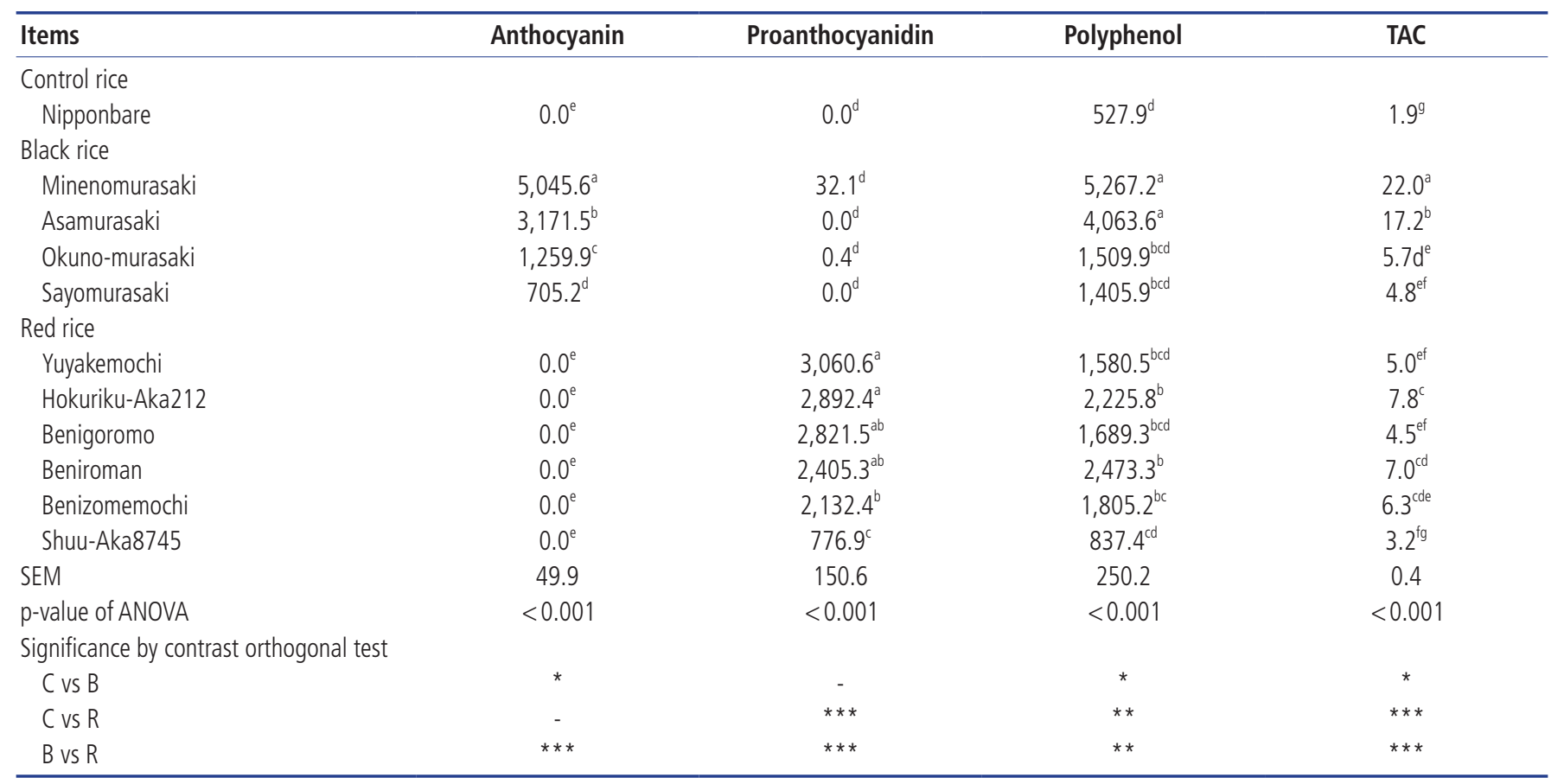

SEM, standard error of the mean; ANOVA, analysis of variance; $C$, control rice group; $B$, black rice group; $R$, red rice group.

The different letters $\left({ }^{(a, b, c, d, e, f, g}\right)$ in the same column differ $(p<0.05$, Tukey test).

${ }^{*} p<0.05,{ }^{* *} p<0.01,{ }^{* * *} p<0.001$ (contrast orthogonal test).

the rice cultivars are presented. Anthocyanin was only significantly $(\mathrm{p}<0.05)$ detected in the black rice group than the control and red rice groups; the highest concentration was in Minenomurasaki $(5,045.6 \mu \mathrm{g} / \mathrm{g})$. Significantly $(\mathrm{p}<0.001)$ higher concentrations of proanthocyanidin were observed in the red rice group than in the control and black rice groups, with Yuyakemochi showing the highest concentration $(3,060.6$ $\mu \mathrm{g} / \mathrm{g})$. The control rice group showed the significantly $(\mathrm{p}<0.05)$ lowest polyphenol content and TAC value in comparison with the colored rice groups.

\section{Correlation between values associated with antioxidant property}

As shown in Table 3, the anthocyanin content in the black and control rice cultivars and the proanthocyanidin content in the red and control rice cultivars correlated positively to the poly-

Table 3. Correlations ( $r$ ) among anthocyanin, proanthocyanidin, polyphenolcontents, and total antioxidant capacity (TAC) in rice cultivars

\begin{tabular}{|c|c|c|}
\hline Items & Polyphenol content & TAC \\
\hline Anthocyanin content ${ }^{1)}$ & $0.990 * *$ & $0.988 * *$ \\
\hline Proanthocyanidin content ${ }^{2)}$ & $0.826^{*}$ & $0.774^{*}$ \\
\hline Polyphenol content ${ }^{3)}$ & - & $0.985^{* * *}$ \\
\hline
\end{tabular}

\footnotetext{
1) In black and control rice cultivars.

${ }^{2)}$ In red and control rice cultivars.

${ }^{3)}$ In all rice cultivars.

${ }^{*} p<0.05,{ }^{* *} p<0.01,{ }^{* * *} p<0.001$.
}

phenol contents with correlation coefficient of 0.990 ( $\mathrm{p}<0.01)$ and $0.826(\mathrm{p}<0.05)$, respectively. There were significantly positive relationships between the TAC values and the anthocyanin content in the black and control rice cultivars $(r=0.988, \mathrm{p}<$ $0.01)$, the proanthocyanidin content in the red and control rice cultivars $(r=0.774, \mathrm{p}<0.05)$, and the polyphenol content in all of the rice cultivars $(r=0.985, \mathrm{p}<0.001)$.

\section{In situ degradability of DM and starch}

For DM degradability (Table 4), the overall p-values of all of the presented items were significant $(\mathrm{p}<0.001)$. The values of $a$ and $b$ fractions were significantly $(\mathrm{p}<0.05)$ lower and higher in the rice grains than in the control feed grains, respectively. The values of $\mathrm{c}$ and $\mathrm{ED}$ in the rice grains were in the range of 0.111 to $0.204 / \mathrm{h}$ and $72.5 \%$ to $81.1 \%$, respectively. The potential degradable fraction $(a+b)$ and the actual degradability at $48 \mathrm{~h}$ incubation showed high values $(>95.8 \%$ and $>96.9 \%$, respectively) without a significant difference $(\mathrm{p}>0.05)$ in the rice grains.

For starch degradability (Table 5 ), the overall p-values of the presented items except for $a+b$ and the actual degradability were significant $(\mathrm{p}<0.001)$. The values of $a$ and $b$ fractions were significantly $(p<0.05)$ lower and higher in the rice grains than in the control feed grains, respectively. The values of $c$ and $\mathrm{ED}$ in the rice grains varied between 0.117 to $0.199 / \mathrm{h}$ and $72.2 \%$ to $81.8 \%$, respectively. Significant main effects were not observed in the values of $a+b$ and actual degradability ( $\mathrm{p}>0.05)$. 
Table 4. Ruminal dry matter degradability of rice, maize, barley, and wheat grains ( $\%$ or as stated)

\begin{tabular}{|c|c|c|c|c|c|c|}
\hline \multirow{2}{*}{ Items } & \multicolumn{5}{|c|}{ Model parameters ${ }^{1)}$} & \multirow{2}{*}{ Actual degradability ${ }^{2)}$} \\
\hline & $a$ & $b$ & $c(/ h)$ & $a+b$ & ED & \\
\hline \multicolumn{7}{|l|}{ Control rice } \\
\hline \multicolumn{7}{|l|}{ Black rice } \\
\hline Minenomurasaki & $16.0^{d}$ & $82.7^{\mathrm{a}}$ & $0.170^{b c}$ & $98.7^{\mathrm{a}}$ & $79.8^{\mathrm{abc}}$ & $98.1^{\mathrm{a}}$ \\
\hline Asamurasaki & $19.5^{d}$ & $79.2^{\mathrm{a}}$ & $0.111^{\mathrm{cd}}$ & $98.7^{\mathrm{a}}$ & $73.2^{\mathrm{bc}}$ & $98.3^{\mathrm{a}}$ \\
\hline Sayomurasaki & $15.0^{d}$ & $80.8^{\mathrm{a}}$ & $0.174^{\mathrm{bc}}$ & $95.8^{\mathrm{abc}}$ & $77.7^{\mathrm{abc}}$ & $96.9^{\mathrm{ab}}$ \\
\hline \multicolumn{7}{|l|}{ Red rice } \\
\hline Yuyakemochi & $18.8^{d}$ & $80.1^{\mathrm{a}}$ & $0.125^{c}$ & $98.9^{\mathrm{a}}$ & $76.0^{b c}$ & $98.1^{\mathrm{a}}$ \\
\hline Hokuriku-Aka212 & $14.9^{d}$ & $82.4^{a}$ & $0.120^{\text {cd }}$ & $97.3^{\mathrm{ab}}$ & $72.5^{c}$ & $96.9^{a b}$ \\
\hline Benigoromo & $17.5^{\mathrm{d}}$ & $79.0^{\mathrm{a}}$ & $0.156^{b c}$ & $96.5^{a b c}$ & $77.0^{\mathrm{bc}}$ & $97.7^{\mathrm{ab}}$ \\
\hline Barley & $42.1^{\mathrm{a}}$ & $48.7^{d}$ & $0.133^{b c}$ & $90.8^{d}$ & $77.5^{\mathrm{bc}}$ & $92.2^{c}$ \\
\hline Wheat & $27.3^{c}$ & $66.8^{b}$ & $0.364^{\mathrm{a}}$ & $94.2^{\mathrm{bcd}}$ & $86.0^{\mathrm{a}}$ & $95.6^{b}$ \\
\hline SEM & 1.3 & 1.4 & 0.02 & 0.7 & 1.7 & 0.5 \\
\hline$p$-value of ANOVA & $<0.001$ & $<0.001$ & $<0.001$ & $<0.001$ & $<0.001$ & $<0.001$ \\
\hline
\end{tabular}

SEM, standard error of the mean; ANOVA, analysis of variance.

1) $a$, soluble and very rapidly degradable fraction; $b$, slowly degradable fraction; $c$, fractional degradation rate of $b$; ED, effective degradability with rate of passage assumed at 0.05/h.

${ }^{2)}$ Actual in situ degradability at $48 \mathrm{~h}$.

The different letters $(a, b, c, d)$ in the same column differ $(p<0.05$, Tukey test).

Table 5. Ruminal starch degradability of rice, maize, barley, and wheat grains (\% or as stated)

\begin{tabular}{|c|c|c|c|c|c|c|}
\hline \multirow{2}{*}{ Items } & \multicolumn{5}{|c|}{ Model parameters ${ }^{1)}$} & \multirow{2}{*}{ Actual degradability ${ }^{2}$} \\
\hline & $a$ & $b$ & $c(/ h)$ & $a+b$ & ED & \\
\hline \multicolumn{7}{|l|}{ Control rice } \\
\hline \multicolumn{7}{|l|}{ Black rice } \\
\hline Minenomurasaki & $4.1^{\text {de }}$ & $95.8^{\mathrm{ab}}$ & $0.175^{c}$ & 99.8 & $78.5^{c}$ & 99.9 \\
\hline Asamurasaki & $9.6^{b c}$ & $90.3^{\mathrm{bcd}}$ & $0.117^{\mathrm{cd}}$ & 99.9 & $72.4^{\text {cd }}$ & 99.7 \\
\hline Sayomurasaki & $4.7^{\mathrm{de}}$ & $94.4^{\mathrm{abc}}$ & $0.170^{\text {cd }}$ & 99.2 & $77.7^{c}$ & 99.9 \\
\hline \multicolumn{7}{|l|}{ Red rice } \\
\hline Yuyakemochi & $11.0^{\mathrm{bc}}$ & $88.9^{\text {cd }}$ & $0.157^{\text {cd }}$ & 99.9 & $78.0^{c}$ & 99.9 \\
\hline Hokuriku-Aka212 & $2.6^{e}$ & $97.3^{\mathrm{a}}$ & $0.141^{\text {cd }}$ & 99.9 & $72.2^{\text {cd }}$ & 99.9 \\
\hline Benigoromo & $9.9^{b c}$ & $87.9^{d}$ & $0.160^{\text {cd }}$ & 97.7 & $76.4^{\text {cd }}$ & 98.5 \\
\hline Beniroman & $1.7^{\mathrm{e}}$ & $98.1^{\mathrm{a}}$ & $0.138^{\text {cd }}$ & 99.8 & $72.3^{\mathrm{cd}}$ & 99.9 \\
\hline Barley & $31.5^{\mathrm{a}}$ & $66.8^{e}$ & $0.321^{b}$ & 98.3 & $89.0^{\mathrm{ab}}$ & 99.7 \\
\hline Wheat & $29.6^{\mathrm{a}}$ & $70.1^{\mathrm{e}}$ & $0.493^{\mathrm{a}}$ & 99.7 & $93.1^{a}$ & 99.9 \\
\hline SEM & 0.9 & 1.1 & 0.024 & 0.6 & 2.0 & 0.4 \\
\hline$p$-value of ANOVA & $<0.001$ & $<0.001$ & $<0.001$ & 0.141 & $<0.001$ & 0.195 \\
\hline
\end{tabular}

SEM, standard error of the mean; ANOVA, analysis of variance.

1) $a$, soluble and very rapidly degradable fraction; $b$, slowly degradable fraction; $c$, fractional degradation rate of $b$; $E D$, effective degradability with rate of passage assumed at $0.05 / h$.

${ }^{2)}$ Actual in situ degradability at $48 \mathrm{~h}$.

The different letters $\left({ }^{a, b, c, d, e}\right)$ in the same column differ $(p<0.05$, Tukey test). 


\section{Correlation between chemical compositions and digestion characteristics}

There were no significant $(\mathrm{p}>0.05)$ correlations between the amylose content and amylose/amylopectin ratio, and in situ degradability model parameters (values of $a$ and $b$ fractions, $c, a+b, \mathrm{ED}$, and actual degradability of $\mathrm{DM}$ and starch). A significant positive correlation was observed between the actual degradabilities of DM and starch at each incubation time ( $r=$ $0.999, \mathrm{p}<0.0001$ ).

\section{DISCUSSION}

Rice grain (without pigment), when used as a ruminant feed, can be an alternative to common grains such as maize, barley, and wheat because of its high starch contents [1]. The starch contents of the colored rice cultivars $(73.5 \%$ to $79.6 \%)$ were similar to those of the control rice cultivars in the present study and in previously reported studies [20,21], which showed values ranging from $71.9 \%$ to $78.7 \%$. Thus, colored rice grains as well as pigment-free rice grain can act as sources of starch.

As expected, the black and red rice cultivars contained high concentrations of anthocyanin and proanthocyanidin, respectively, whereas the control rice cultivar had neither pigment in the present study. Additionally, a wide range of differences in the anthocyanin (705 to $5,046 \mu \mathrm{g} / \mathrm{g}$ ) and proanthocyanidin contents (777 to $3,061 \mu \mathrm{g} / \mathrm{g}$ ) between the colored rice cultivars was observed. In line with these results, previous studies found varietal differences in the pigment contents of colored rice cultivars [7]. Other factors affecting the pigment contents of colored rice grains have been reported to include air temperature during the ripening period and the nitrogen fertilizer level [22]. However, Ito et al [23] suggested that varietal differences are more responsible than the cultivation conditions for the pigment contents in colored rice grains. Actually, in the selected colored-rice cultivars studied in previous reports [7], the same rank order of pigment concentrations was observed: Asamurasaki>Okuno-murasaki in terms of the anthocyanin concentration, and Beniroman $>$ Benizomemochi in terms of the proanthocyanidin concentration.

The significantly positive relationships among the pigment contents, polyphenol contents and TAC values in the rice cultivars in the present study indicate that the pigment contents have additional contribution to the increased polyphenol content and TAC values in the colored rice grains. These results correspond to those of previous reports which used different colored rice cultivars than the present study [23]. Pigment-fee rice grains include antioxidants such as vitamin $\mathrm{E}$, and colored rice grains contain similar levels of vitamin E [7]. Based on the USDA database [24], rice grain without pigment have been classified into a group having higher TAC value in grains. Therefore, colored rice grains, whose TAC values were enhanced by their increased pigment contents in comparison to the control rice grain, would be a rich source of antioxidants.

In rice grains, the in situ degradation characteristics of DM should be well represented by the degradation characteristics of starch because starch is surely the principal chemical component $(>73.5 \%)$. Indeed, there was a significantly positive correlation between the DM and starch degradabilities at each incubation time in the present study. Based on the results of previous publications $[8,20,25]$, differences have been found in ruminal degradation characteristics of feed grains between plant species. In the present study, the degradation characteristics represented as $c$ and ED were ranked in the following order: wheat $>$ barley $\geq$ rice $>$ maize. This order agrees with the findings of the above-mentioned reports $[8,20]$. The present findings therefore confirm the degradation characteristics of rice grains relative to those of commonly-used grains, and demonstrate that colored rice grains show similar degradation characteristics to rice grains without pigment under the in situ condition.

The results of the present study revealed that colored rice cultivars show wide-ranging degradation characteristics as represented by $c$ and ED. According to a previous review [26], many factors affect the starch degradability in feed grains. Among those factors, the chemical properties of the starch (amylopectin/amylose), the extent of starch-protein interaction, and the physical structure of the granules are probably associated with starch degradability in rice cultivars. Enishi et al [21] found that a higher amylose content without difference in total starch content decreased starch degradability but protein content, which varied due to fertilizer application, had no effect on the rice grains. However, in the present study, no significant relationships between amylose content and amylose/amylopectin ratio, and starch degradation characteristics such as $c$ and ED were observed, which corresponds to the findings reported by Miyaji et al [8]. This contradiction may be due to following reason: Enishi et al [21] used rice cultivars that had almost the same genetic background except for the amylose content gene in order to focus on the effect of the amylose content, whereas the present study involved rice cultivars from different areas with several genetic backgrounds. Additionally, Miyaji et al [8] found that there were wide variations in the $a$ and ED values between rice cultivars without pigment, and pointed out that those variations were likely due to the physical structure of the granules [27]. A previous report [8] supports the findings of the present study in which the $a$ and $\mathrm{ED}$ values varied widely in colored rice cultivars. Taken together, we suggest that the physical structure of the granule is likely to be responsible for the difference in degradation characteristics between the colored rice cultivars in the present study.

Although rice gains require some kinds of processing such as grinding and steam-flaking in order to be digested in the rumen since unprocessed rice grains were almost indigested 
under in situ conditions, grinding with a 2-mm screen as was done in the present study should maximize the starch digestion of starch from rice grains [8]. Actually, most of the DM and starch in rice grains was ruminally degraded as indicated by the values of potential degradable fraction $(a+b)$ and actual degradability at $48 \mathrm{~h}$ incubation. Furthermore, the present result also shows that most of the pigments in the colored rice grains were released to the ruminal fluid. Our previous publications $[28,29]$ indicated that the studied pigment-rich forages (anthocyanin-rich whole crop corn and purple whole crop rice), which would improve the oxidative status markers in ruminants, contain their pigments in the fibrous parts of the plants such as the stem and leaf. They also implied that those pigment-rich forages may have supplied less pigment to the animals than their pigment contents because of the generically lower digestibility of fiber fractions. Therefore, given their high digestibility, colored rice grains would be excellent pigment sources that could efficiently supply pigment to ruminants.

As mentioned above, the present study showed that colored rice grains would be good pigment sources because of their high pigment contents and high digestibility. There are many previous reports that studied the effects of antioxidants such as anthocyanin and proanthocyanidin on productivity and health in monogastric animals [30] but a few in ruminant animals. With regard to proanthocyanidins, they are also known as condensed tannins. Since proanthocyanidins have a functional property to bind preferentially to proteins to form ruminally-indigestible complexes, they show both positive and negative effects on nutrient availability depending on their concentrations and type in ruminants $[31,32]$. As for anthocyanins, feeding of anthocyanin-rich diets have been reported to improve oxidative stress markers [29,33]. In addition, Di Trana et al [34] found that polyphenol-rich diet ingestions led to increase in polyphenol content and TAC in both plasma and milk in lactating goat. It has been reported that lipid oxidation in milk, which give rise to bad odor, was suppressed by antioxidant supplementation in dairy cow [35]. Taken together, antioxidants in diets may be absorbed and bring benefits to productivity and quality in ruminant animals. However, it appears that the antioxidants' actions depend on their concentration in diet and nature of antioxidant. Thus, in any case, feeding studies of colored rice grains should be conducted to elucidate this.

\section{CONCLUSION}

The findings of the present study demonstrated that colored rice grains contained higher concentrations of pigments which resulted in additional contributions to the increased polyphenol content and TAC values. Based on the ruminal degradation characteristics observed in the present study, the colored rice grains as well as the control rice grain contained most-digestible starch as expressed by their maximum values of the potential degradable fraction $(a+b)$. Their $c$ and ED values, which represent degradation characteristics, for starch were ranked as follows: wheat $>$ barley $\geq$ rice $>$ maize. Thus, colored rice grains should have high potential as sources of antioxidants in addition to being sources of starch for ruminants.

\section{CONFLICT OF INTEREST}

We certify that there is no conflict of interest with any financial organization regarding the material discussed in the manuscript.

\section{ACKNOWLEDGMENTS}

The donations of grain samples by Dr. Nakagomi, Western Region Agricultural Research Center, NARO (Asamurasaki, Okuno-murasaki, Yuyakemochi, and Benigoromo), Aichi Agricultural Research Center (Minenomurasaki), and JA Higashinihon Kumiai Shiryo Co. (maize, barley, and wheat) are gratefully acknowledged. The authors are grateful to Dr. Y. Kaji, Kyushu Okinawa Agricultural Research Center, NARO, for his valuable advice on the manuscript. Thanks also to the members of the Animal Management Section, Institute of Livestock and Grassland Science, NARO (NILGS), for animal management, and to Ms. C. Nagasawa, NILGS, for her skilled technical assistance in collecting and analyzing the samples. This work was partly supported by a grant from the Research for production of valuable livestock by feeding self-sufficient forage crops' project of The Ministry of Agriculture, Forestry and Fisheries of Japan.

\section{REFERENCES}

1. Miyaji M, Matsuyama H, Hosoda K. Effect of substituting brown rice for corn on lactation and digestion in dairy cows fed diets with a high proportion of grain. J Dairy Sci 2014;97: 952-60.

2. The 90th statistical yearbook of Ministry of Agriculture, Forestry and Fisheries [Internet]. Ministry of Agriculture, Forestry and Fisheries; 2016 [cited $2018 \mathrm{Feb} 2$ ]. Available from: http:// www.maff.go.jp/e/data/stat/90th/index.html\#7

3. Lykkesfeldt J, Svendsen O. Oxidants and antioxidants in disease: oxidative stress in farm animals. Vet J 2007;173:502-11.

4. Bernabucci U, Ronchi B, Lacetera N, Nardone A. Markers of oxidative status in plasma and erythrocytes of transition dairy cows during hot season. J Dairy Sci 2002;85:2173-9.

5. Abdel-Aal E-SM, Young JC, Rabalski I. Anthocyanin composition in black, blue, pink, purple, and red cereal grains. J Agric Food Chem 2006;54:4696-704.

6. Oki T, Masuda M, Kobayashi M, et al. Polymeric procyanidins as radical-scavenging components in red-hulled rice. J Agric 
Food Chem 2002;50:7524-9.

7. Mizobuchi R, Okamoto M, Kaji R, et al. New rice cultivar "Benizomemochi”. Bull Natl Agric Res Cent Kyushu Okinawa Reg 2006;46:15-38.

8. Miyaji M, Nonaka K, Matsuyama H, Hosoda K, Kobayashi R. Effects of cultivar and processing method of rice grain on ruminal disappearance characteristics. Jpn J Grassl Sci 2010; 56:13-9.

9. NARO (National Agriculture and Food Research Organization). Japanese feeding standard for beef cattle. Tokyo, Japan: Japan Livestock Industry Association; 2008.

10. Ørskov ER, McDonald I. The estimation of protein degradability in the rumen from incubation measurements weighted according to rate of passage. J Agric Sci 1979;92:499-503.

11. McDonald I. A revised model for the estimation of protein degradability in the rumen. J Agric Sci 1981;96:251-2.

12. AOAC. Official methods of analysis of AOAC International. 18th ed. Arlington, VA, USA: AOAC International; 2005.

13. Van Soest PJ, Robertson JB, Lewis BA. Methods for dietary fiber, neutral detergent fiber, and nonstarch polysaccharides in relation to animal nutrition. J Dairy Sci 1991;74:3583-97.

14. Juliano BO. A simplified assay for milled-rice amylose. Cereal Sci Today 1971;16:334-40.

15. Lee J, Durst RW, Wrolstad RE. Determination of total monomeric anthocyanin pigment content of fruit juices, beverages, natural colorants, and wines by the $\mathrm{pH}$ differential method: collaborative study. J AOAC Int 2005;88:1269-78.

16. Sun B, Ricardo-de-Silva JM, Spranger I. Critical factors of vanillin assay for catechins and proanthocyanidins. J Agric Food Chem 1988;46:4267-74.

17. Suda I, Oki T, Nishiba Y, et al. Polyphenol contents and radicalscavenging activity of extracts from fruits and vegetables in cultivated in Okinawa, Japan. Nippon Shokuhin Kagaku Kogaku Kaishi 2005;52:462-71.

18. Oki T, Masuda M, Furuta S, et al. Involvement of anthocyanins and other phenolic compounds in radical-scavenging activity of purple-fleshed sweet potato cultivars. J Food Sci 2002;67: 1752-6.

19. SAS (Statistical Analysis Systems Institute). SAS/STAT 9.2 user's guide. Cary, NC, USA: SAS Institute; 2008.

20. Enishi O, Terada F, Ishikawa T. Chemical composition and ruminal disappearance characteristics of grains for cattle feed. Grassl Sci 2000;46:305-8.

21. Enishi O, Terada F, Ishikawa T. The effect of amylose content and level of nitrogen application on ruminal disappearance characteristics of brown rice. Grassl Sci 2002;47:599-603.

22. Kobayashi A, Shimizu H, Kuroda M. Effect of mean air tem- perature during ripening period on pigment contents of darkpurple rice. Hokuriku Crop Sci 2001;36:33-5.

23. Ito M, Ohara E, Kobayashi A, et al. Antioxidant capacities and polyphenol content of colored rice cultivars. Nippon Shokuhin Kagaku Kogaku Kaishi 2011;58:576-82.

24. USDA (U.S. Department of Agriculture, Agricultural Research Service). Oxygen radical absorbance capacity (ORAC) of selected foods, Release 2. Beltsville, MD, USA: Nutrient Data Laboratory; 2010.

25. Herrera-Saldana RE, Huber JT, Poore MH. Dry matter, crude protein, and starch degradability of five cereal grains. J Dairy Sci 1990;73:2386-93.

26. Rooney LW, Pflugfelder RL. Factors affecting starch digestibility with special emphasis on sorghum and corn. J Anim Sci 1986; 63:1607-23.

27. Tashiro T, Ebata M. Studies on white-belly rice kernel. IV. Opaque rice endosperm viewed with a scanning electron microscope. Proc Crop Sci Soc Japan 1975;44:205-14.

28. Hosoda K, Eruden B, Matsuyama H, Shioya S. Effect of anthocyanin-rich corn silage on digestibility, milk production and plasma enzyme activities in lactating dairy cows. Anim Sci J 2012;83:453-9.

29. Hosoda K, Matsuo M, Miyaji M, et al. Fermentative quality of purple rice (Oryza sativa L.) silage and its effects on digestibility, ruminal fermentation and oxidative status markers in sheep. Grassl Sci 2012;58:161-9.

30. Tsuda T. Recent progress in anti-obesity and anti-diabetes effect of berries. Antioxidants 2016;5:E13.

31. Reed JD, Soller H, Woodward A. Fodder tree and straw diets for sheep: intake, growth, digestibility and the effects of phenolics on nitrogen utilization. Anim Feed Sci Technol 1990;30: 39-50.

32. Aerts RJ, Barry TN, McNabb WC. Polyphenols and agriculture: beneficial effects of proanthocyanidins in forages. Agric Ecosyst Environ 1999;75:1-12.

33. Hosoda K, Miyaji M, Matsuyama H, et al. Effect of supplementation of purple pigment from anthocyanin-rich corn (Zea mays L.) on blood antioxidant activity and oxidation resistance in sheep. Livest Sci 2012;145:266-70.

34. Di Trana A, Bonanno A, Cecchini S, et al. Effects of Sulla forage (Sulla coronarium L.) on the oxidative status and milk polyphenol content in goats. J Dairy Sci 2015;98:37-46.

35. Aoki N, Furukawa S, Sato K, et al. Supplementation of the diet of dairy cows with trehalose results in milk with low lipid peroxide and high antioxidant content. J Dairy Sci 2010;93: 4189-95. 